\title{
Contaminação bacteriana de estetoscópios das unidades de pediatria em um hospital universitário
}

\author{
Bacterial contamination of stethoscopes in pediatric \\ units at a university hospital
}

Marcelo Souza Xavier ${ }^{1}$ e Mariko Ueno ${ }^{2}$

\begin{abstract}
RESUMO
A avaliação da contaminação, de estetoscópios utilizados em setores pediátricos de hospital e emergência, mostrou que 87\% dos estetoscópios apresentaram diafragmas contaminados. 0 microrganismo mais freqüentemente isolado foi Staphylococcus coagulase negativo. A resistência aos antibióticos mostra que o estetoscópio deve ser considerado um importante veículo de bactérias resistentes aos antibióticos.
\end{abstract}

Palavras-chaves: Diafragma de estetoscópios. Desinfecção. Resistência aos antibióticos.

\section{ABSTRACT}

Evaluation of the contamination of stethoscopes used in pediatric units of a hospital and emergency service showed that $87 \%$ of them presented contaminated diaphragms. Coagulase-negative Staphylococcus was the microorganism most frequently isolated. The resistance to antibiotics indicates that stethoscopes should be considered to be an important vehicle for disseminating bacteria resistant to antibiotics.

Key-words: Stethoscope diaphragm. Disinfection. Resistance to antibiotics.

0 estetoscópio é um veículo ao qual não se confere importância, apesar da sua comprovada contaminaçãa $0^{1314} \mathrm{e}$ do seu papel na transmissão de microrganismos ${ }^{311}$. Coberturas de prata não protegem os diafragmas dos estetoscópios da contaminação ${ }^{12}$. 0 microrganismo mais freqüente nos estetoscópios é o Staphylococcus coagulase negativo ${ }^{79}$.

Neste estudo, foram avaliados 38 estetoscópios: 6 da UTIneonatal, 6 da UTI-pediátrica, 5 da UTI-pediátrica semi-intensiva, 5 do Ambulatório Pediátrico, 6 da Enfermaria Pediátrica, 5 do Isolamento Pediátrico e 5 do Pronto Socorro Infantil.

As amostras foram coletadas com swab embebido em solução fisiológica, semeadas em ágar sangue (DIFCO) e incubadas a $35^{\circ} \mathrm{C}$; este procedimento foi realizado antes e após a desinfecção. A escolha do desinfetante foi randomizada e 12 foram desinfetados com álcool 70\%, 13 com álcool iodado e 13 com hipoclorito de sódio (100ppm) e os resultados foram analisados estatisticamente utilizando o teste t. Foi realizada a prova de sensibilidade aos antibióticos para as cepas isoladas após a desinfecção.

0 questionário aplicado, aos profissionais, sobre frequiência de desinfecção mostrou que $71,1 \%$ dos entrevistados afirmaram realizar a desinfecção dos estetoscópios, 23 (60,5\%) a faziam após

1. Departamento de Medicina, Universidade de Taubaté, Taubaté, SP. 2. Instituto Básico de Biociências, Universidade de Taubaté, Taubaté, SP.

Endereço para correspondência: Dra. Mariko Ueno. Instituto Básico de Biociências/ UNITAU. Rua Tiradentes 500, Campus Bom Conselho, 12030-180 Taubaté, SP.

Tel: 5512 3629-7909

e-mail: mariueno@unitau.br

Recebido para publicação em 12/05/2008

Aceito em 27/01/2009 cada paciente. A frequiência de desinfecção dos estetoscópios entre os residentes e os internos foi maior que a dos médicos, resultado semelhante ao de Smith e cols ${ }^{9}$ que descreveram que com 0 passar do tempo o cuidado, do profissional, com a desinfecção do estetoscópio diminuiu. A desinfecção diária ou semanal dos estetoscópios era realizada por $48 \%$ dos profissionais ${ }^{4}$ e por $6 \%$ dos estudantes de medicina 5 .

0 nível de contaminação dos diafragmas dos estetoscópios vem se mantendo, Smith e cols ${ }^{9}$, Araújo e cols ${ }^{1}$ e Maluf e cols ${ }^{6}$ encontraram níveis de contaminação de 86,1\%, 97,9\% e 87\%, respectivamente. Neste estudo, 33 (86,8\%) estetoscópios amostrados estavam contaminados. Cinco estetoscópios apresentaram diafragmas livres de microrganismos, sendo duas da UTI neonatal e quatro da Enfermaria Pediátrica, nas outras cinco unidades $100 \%$ dos estetoscópios estavam contaminados e aqueles do Pronto Socorro apresentaram diafragmas com o maior nível de contaminação. 0 microrganismo mais freqüentemente isolado foi Staphylococcus coagulase negativa, presentes em estetoscópios de todos os setores. 0 nível de contaminação e frequiência de Staphylococcus coagulase negativa, coincidem com relatos anteriores ${ }^{169}$. Não foi isolado Staphylococcus aureus, igualmente ao trabalho de Sanders ${ }^{8}$ resistentes à meticilina (MRSA), embora alguns relatos indiquem a sua presença ${ }^{1510}$.

A desinfecção eliminou microrganismos dos diafragmas dos estetoscópios da UTI neonatal e do Ambulatório Pediátrico; para os demais, houve expressiva redução da contaminação. Os desinfetantes apresentaram resultados, estatisticamente significantes, com base no nível de 5\%; o hipoclorito de sódio $(100 \mathrm{ppm})(\mathrm{p}=0,0005)$, o álcool iodado $(\mathrm{p}=0,0007)$ e 0 
álcool $(70 \%)(\mathrm{p}=0,0010)$ foram eficazes quanto à desinfecção dos estetoscópios. A eficiência da desinfecção com álcool $70 \%$ foi semelhante à apresentada por Bernard e cols ${ }^{2}$ e Jones e cols ${ }^{4}$, entretanto, o uso de hipoclorito de sódio apresentou maior eficiência, do que aquele apresentado por Marinella e cols ${ }^{7}$.

As cepas isoladas após a desinfecção apresentaram resultados variados quanto à sensibilidade aos antibióticos (Tabela 1). Aquelas provenientes de diafragmas de estetoscópios das UTIs e do isolamento pediátrico apresentaram resistência aos

\section{TABELA 1}

Sensibilidade das cepas, isoladas de membrana de estetoscópios, após desinfecção, aos antibióticos.

\begin{tabular}{|c|c|c|c|c|c|c|}
\hline \multirow[b]{2}{*}{ Antibióticos } & \multicolumn{2}{|c|}{$\begin{array}{c}\text { Staphylococcus spp } \\
\left(\mathrm{n}^{0}=20\right)\end{array}$} & \multicolumn{2}{|c|}{$\begin{array}{c}\text { Streptococcus spp } \\
\left(\mathrm{n}^{\mathrm{o}}=7\right)\end{array}$} & \multicolumn{2}{|c|}{$\begin{array}{c}\text { Bacilos Gram-positivos } \\
\left(\mathrm{n}^{0}=6\right)\end{array}$} \\
\hline & $\mathrm{n}^{\underline{0}}$ & $\%$ & $\mathrm{n}^{0}$ & $\%$ & $\mathrm{n}^{0}$ & $\%$ \\
\hline \multicolumn{7}{|l|}{$\beta$-lactâmicos } \\
\hline penicilina $\mathrm{G}$ & 9 & 45,0 & 4 & 57,2 & 2 & 33,3 \\
\hline oxacilina & 19 & 95,0 & 5 & 71,4 & 2 & 33,3 \\
\hline amoxicilina & 12 & 60,0 & 7 & 100,0 & 2 & 33,3 \\
\hline ampicilina & 9 & 45,0 & 5 & 71,4 & 2 & 33,3 \\
\hline cefalotina & 14 & 70,0 & 7 & 100,0 & 2 & 33,3 \\
\hline cefuroxime & 10 & 50,0 & 2 & 28,6 & 1 & 16,7 \\
\hline cefoxitina & 19 & 95,0 & 6 & 85,7 & 4 & 66,7 \\
\hline ceftriaxone & 11 & 55,0 & 3 & 42,9 & 3 & 50,0 \\
\hline cefotaxima & 8 & 40,0 & 1 & 14,3 & 3 & 50,0 \\
\hline cefpirom & 13 & 65,0 & 6 & 85,7 & 2 & 33,3 \\
\hline cefadroxil & 16 & 80,0 & 7 & 100,0 & 3 & 50,0 \\
\hline \multicolumn{7}{|l|}{ Glicopeptídeos } \\
\hline vancomicina & 18 & 90,0 & 7 & 100,0 & 6 & 100,0 \\
\hline teicoplanina & 19 & 95,0 & 7 & 100,0 & 5 & 83,3 \\
\hline \multicolumn{7}{|l|}{ Aminoglicosídeos } \\
\hline gentamicina & 18 & 90,0 & 6 & 85,7 & 6 & 100,0 \\
\hline tobramicina & 19 & 95,0 & 7 & 100,0 & 6 & 100,0 \\
\hline amicacina & 17 & 85,0 & 6 & 85,7 & 5 & 83,3 \\
\hline eritromicina & 12 & 60,0 & 6 & 85,7 & 5 & 83,3 \\
\hline azitromicina & 17 & 85,0 & 6 & 85,7 & 5 & 83,3 \\
\hline \multicolumn{7}{|l|}{ Quinolonas } \\
\hline ácido nalidíxico & 16 & 80,0 & 6 & 85,7 & 6 & 100,0 \\
\hline norfloxacina & 20 & 100,0 & 6 & 85,7 & 5 & 83,3 \\
\hline Imipenem & 19 & 95,0 & 6 & 85,7 & 5 & 83,3 \\
\hline Trimetoprin & 11 & 55,0 & 6 & 85,7 & 2 & 33,3 \\
\hline Tetraciclina & 19 & 95,0 & 6 & 85,7 & 5 & 83,3 \\
\hline
\end{tabular}

antibióticos, sobretudo àqueles da classe dos $\beta$-lactâmicos; enquanto aquelas isoladas de estetoscópios do Ambulatório Pediátrico apresentaram-se sensíveis. Aproximadamente 95\% dos Staphylococcus spp e 70\% dos Streptococcus spp apresentaram sensibilidade à oxacilina; uma e duas cepas de Staphylococcus apresentaram sensibilidade intermediária à vancomicina e teicoplanina, respectivamente; os glicopeptídeos são utilizados em infecções graves, constituindo uma opção terapêutica segura para infecções causadas por este microrganismo.

Os achados deste trabalho apontam que os estetoscópios dos setores pediátricos deste Hospital devem ser considerados como fômites importantes na transmissão de bactérias resistentes aos antibióticos e a prática da desinfecção deve ser considerada.

\section{REFERÊNCIAS}

1. Araujo BAC, Oliveira AL, Santos Filho L. Isolamento de amostras multirresistentes de Staphylococcus aureus em estetoscópios usados no ambiente hospitalar. Sociedade Brasileira de Angiologia e Cirurgia Vascular 32: 285-288, 2000.

2. Bernard L, Kereveur A, Durand D, Gonot J, Goldstein F, Mainardi JL, Acar J, Carlet J. Bacterial contamination of hospital psysician's stethoscopes. Infection Control Hospital Epidemiology 20: 626-628, 1999

3. Breathnach AS, Jenkins DR, Pedler SJ. Stethoscopes as possible vectors of infection by staphylococci. British Medical Journal 305:1573-1574, 1992.

4. Jones J S, Hoerle D, Riekse R. Stethoscopes: a potential vector of infection? Annals Emergency Medicine 26: 296-299, 1995.

5. Madar R, NovakovaE, BaskaT. The role of non-critical helth-care tools in the transmission of nosocomial infections. Bratislavské Lekárske Listy 106: 348-350, 2005.

6. Maluf MEZ, Maldonado AF, Bercial ME, Pedroso SA. Stethoscope: a friend or an enemy? Revista Paulista de Medicina 120: 13-15, 2002

7. Marinella MA, Pierson C, Chenoweth C. The stethoscope: a potential source of nosocomial infection. Archives Internal Medicine 157: 786-790, 1997.

8. Sanders $S$. The stethoscope and cross-infection revisited. The British Journal General Practice 55: 54-55, 2005

9. Smith MA, Mathewson JJ, Ulert A. Contaminated stethoscopes revisited. Archives of Internal Medicine 156: 82-84, 1996.

10. Sood P, Mishra B, Mandal A. Potential infection hazards of stethoscopes. Journal Indian Medical Association 98: 368-370, 2000.

11. Varghese D, Patel H. Hand washing. Stethoscopes and white coats are sources of nosocomial infection. British Medical Journal 319: 519, 1999.

12. Wood MW, Lund RC, Stevenso KB. Bacterial contamination of stethoscopes with antimicrobial diaphragm covers. American Journal Infection Control 35: 263-266, 2007

13. Wright IMR, Orr H, Porter C. Stethoscope contamination in the neonatal intensive care unit. Journal of Hospital Infection 29: 65-68, 1995.

14. Wurtz R, Weinstein R. Microbiologic contamination and cleaning personal medical equipment. Journal of American Medical Association 305:1573-1574, 1998. 